\title{
Erratum to "Fusion Pore Diameter Regulation by Cations Modulating Local Membrane Anisotropy"
}

\author{
Doron Kabaso, ${ }^{1,2}$ Ana I. Calejo, ${ }^{3}$ Jernej Jorgačevski, ${ }^{2,4}$ Marko Kreft, 2, 4, 5 \\ Robert Zorec, ${ }^{2,4}$ and Aleš Iglič ${ }^{1}$ \\ ${ }^{1}$ Laboratory of Biophysics, Faculty of Electrical Engineering, University of Ljubljana, 1000 Ljubljana, Slovenia \\ ${ }^{2}$ Laboratory of Neuroendocrinology-Molecular Cell Physiology, Faculty of Medicine, University of Ljubljana, \\ 1000 Ljubljana, Slovenia \\ ${ }^{3}$ Departamento de Biologia e CESAM, Universidade de Aveiro, 3810-193 Aveiro, Portugal \\ ${ }^{4}$ Celica Biomedical Center, Tehnoloski Park 24, 1000 Ljubljana, Slovenia \\ ${ }^{5}$ Department of Biology, Biotechnical Faculty, University of Ljubljana, Vecna pot 111, 1000 Ljubljana, Slovenia \\ Correspondence should be addressed to Doron Kabaso, doron.kabaso@fe.uni-lj.si
}

Received 2 April 2012; Accepted 22 April 2012

Copyright ( 2012 Doron Kabaso et al. This is an open access article distributed under the Creative Commons Attribution License, which permits unrestricted use, distribution, and reproduction in any medium, provided the original work is properly cited.

After our paper was published online, we found typographical errors in (1), (7), and (8) which should be correctly read as follows:

$$
\begin{gathered}
F=\int\left[\kappa\left(H-H_{m}\right)^{2}+\kappa\left(D-D_{m}\right)^{2}+\sigma\right] d A \\
U=\varphi \frac{\left(-2 C_{1 m}^{2} n^{+} R^{2} \kappa+C_{1 m}^{2} n^{+2} R^{2} \kappa+\left(C_{1 m}^{2} R^{2}-1\right) \kappa+2 R^{2} \sigma\right)}{2 R^{3}}=0 \\
R_{\mathrm{eq}}=\frac{\sqrt{\kappa}}{\sqrt{C_{1 m}^{2}\left(n^{+}-1\right)^{2} \kappa+2 \sigma}} .
\end{gathered}
$$



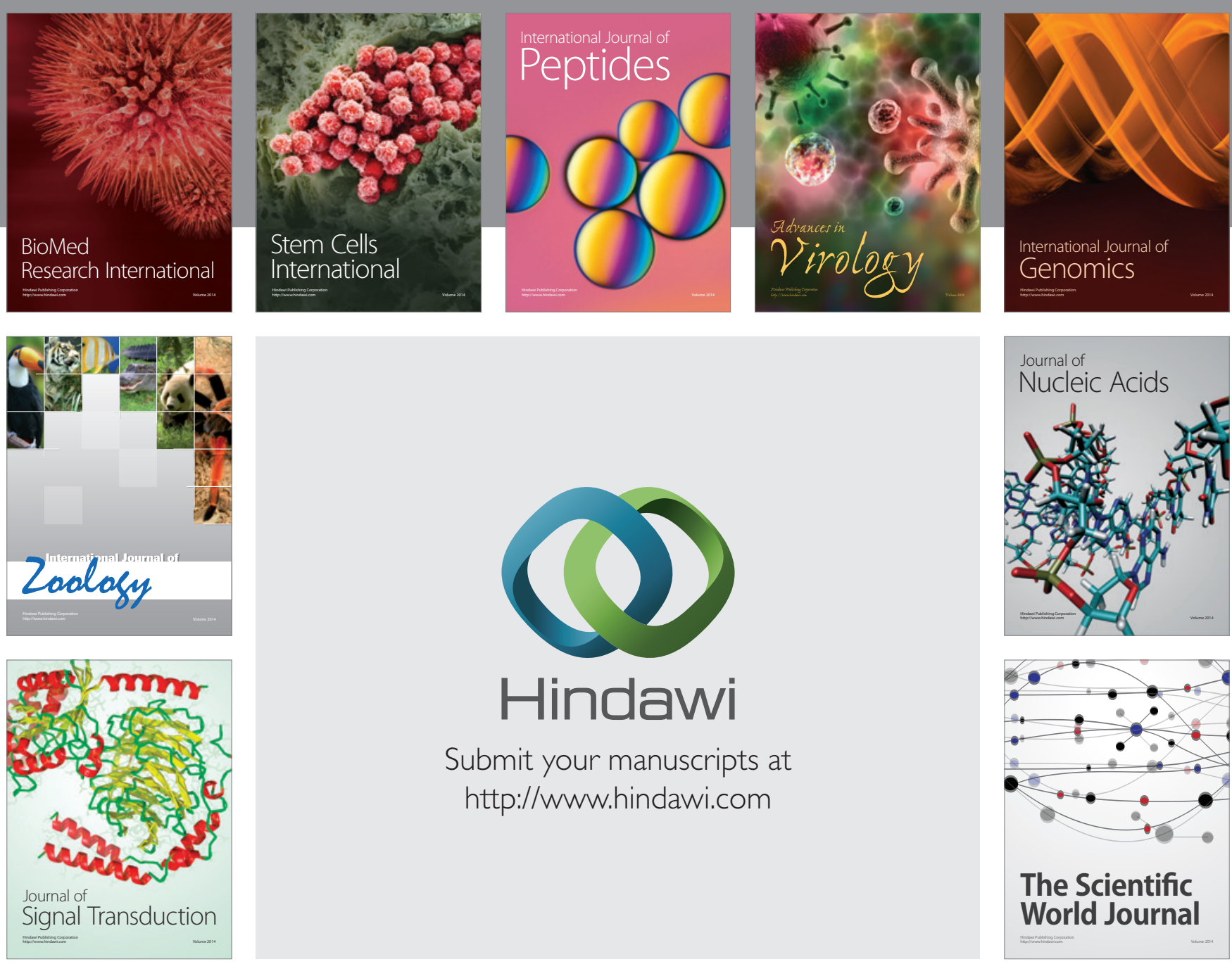

Submit your manuscripts at

http://www.hindawi.com
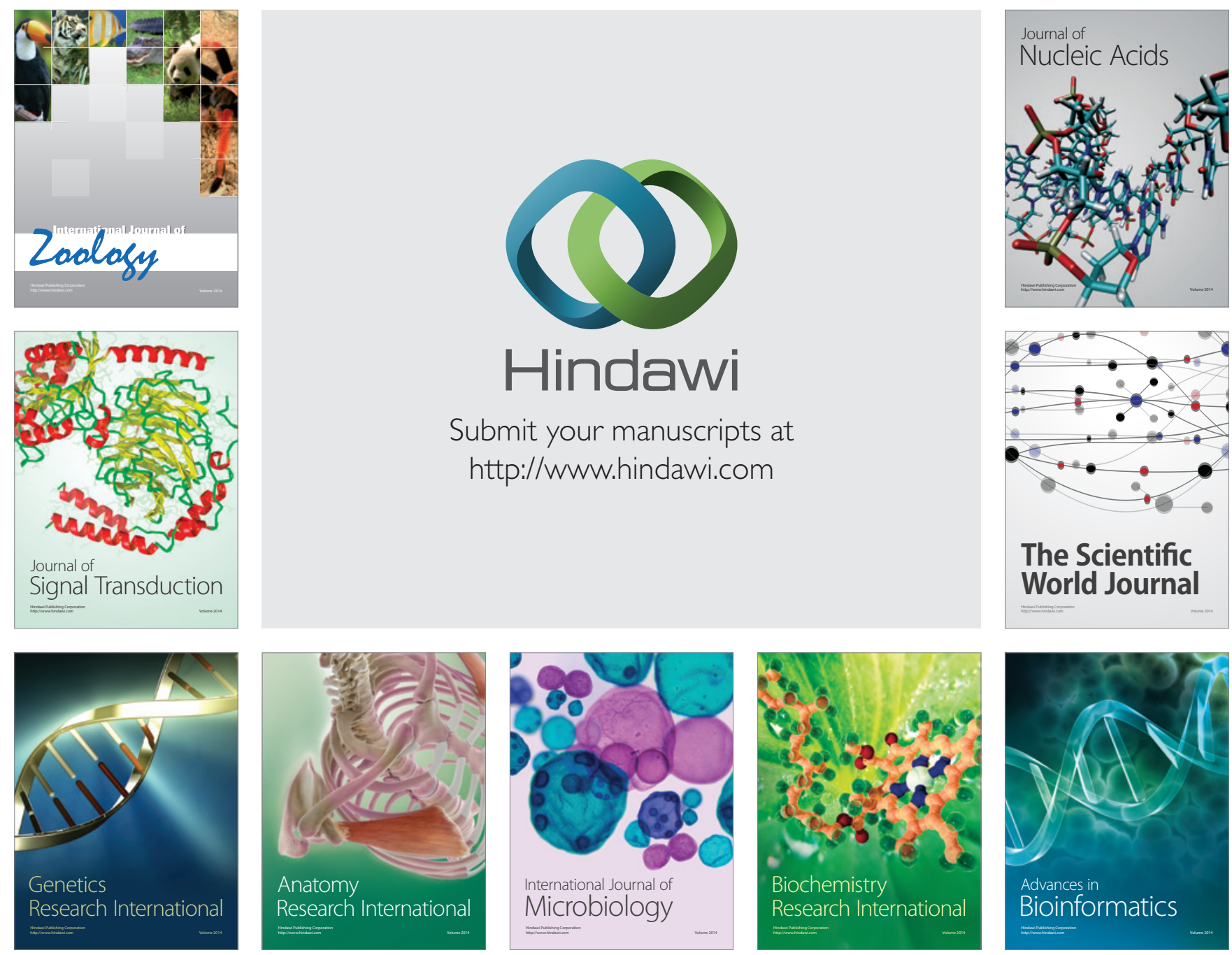

The Scientific World Journal
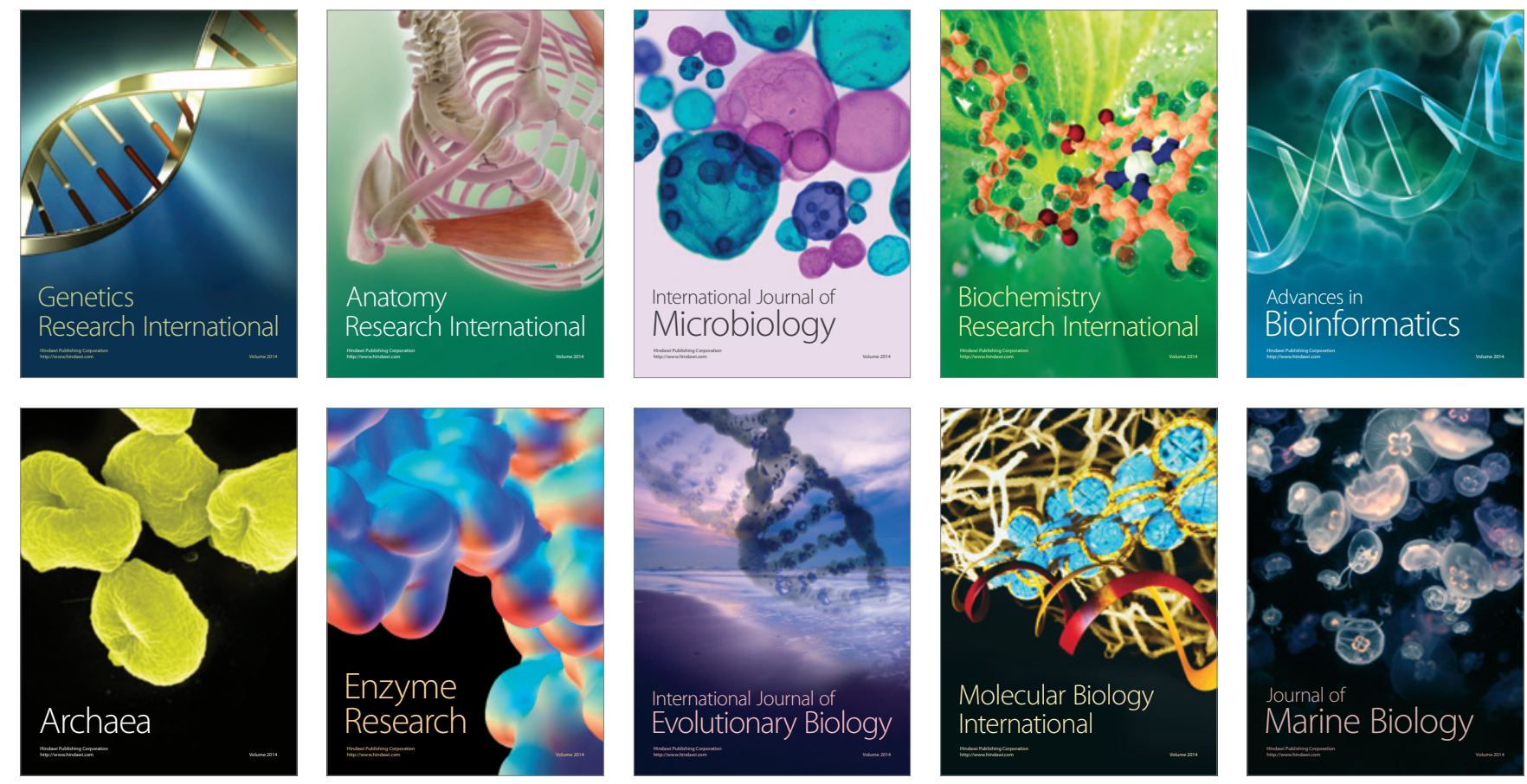